\title{
Dietary, lifestyle and clinicopathological factors associated with BRAF and K-ras mutations arising in distinct subsets of colorectal cancers in the EPIC Norfolk study
}

\author{
Adam Naguib', Panagiota N Mitrou², Laura J Gay', James C Cooke', Robert N Luben², Richard Y Ball³, \\ Alison McTaggart ${ }^{2}$, Mark J Arends ${ }^{4 *}$, Sheila A Rodwell ${ }^{1,2}$
}

\begin{abstract}
Background: BRAF and K-ras proto-oncogenes encode components of the ERK signalling pathway and are frequently mutated in colorectal cancer. This study investigates the associations between BRAF and K-ras mutations and clinicopathological, lifestyle and dietary factors in colorectal cancers.

Methods: 186 adenocarcinomas and 16 adenomas from the EPIC Norfolk study were tested for BRAF and K-ras mutations. Diet and lifestyle data were collected prospectively using seven day food diaries.

Results: BRAF V600E mutation was found in $15.6 \%$ of colorectal cancers but at higher frequencies in cancers with proximal location, poor differentiation and microsatellite instability (MSI) (all $p<0.001$ ). K-ras mutation (mostly in codons 12 and 13) was found in 22.0\% of colorectal cancers but at higher frequencies in cancers of more advanced Dukes' stage $(p=0.001)$, microsatellite stable (MSS) status $(p=0.002)$ and in individuals with lower blood high-density lipoprotein concentrations $(p=0.04)$. Analysis of dietary factors demonstrated no link between BRAF mutation and any specific dietary constituent, however, K-ras mutation was found at higher frequencies in individuals with higher white meat consumption $(p<0.001)$. Further analysis of specific mutation type demonstrated that $\mathrm{G}$ to $\mathrm{A}$ transitions in $\mathrm{K}$-ras were observed at higher frequencies in individuals consuming lower amounts of fruit $(p=0.02)$.
\end{abstract}

Conclusion: These data support the model of BRAF and K-ras mutations arising in distinct colorectal cancer subsets associated with different clinicopathological and dietary factors, acting as mutually exclusive mechanisms of activation of the same signalling pathway.

\section{Background}

$B R A F$ and $K$-ras genes both encode proteins that act in the ERK signalling pathway, which mediates cellular responses to growth factors and regulates elements of the cell cycle, apoptosis and differentiation [1]. Activating mutations in both genes have been found in colorectal cancer with mutation frequencies of $4-13 \%$ for $B R A F$ [2-9] and of 20-50\% for $K$-ras [10-17] having been reported. BRAF and $K$-ras mutations are frequently found to be mutually exclusive in colorectal cancer

\footnotetext{
* Correspondence: mja40@cam.ac.uk
${ }^{4}$ Department of Pathology, University of Cambridge, Addenbrooke's Hospital,

* Correspondence: mja40@cam.ac.uk
${ }^{4}$ Department of Pathology, University of Cambridge, Addenbrooke's Hospital, Cambridge CB2 2QQ, UK
}

(c) 2010 Naguib et al; licensee BioMed Central Ltd. This is an Open Access article distributed under the terms of the Creative Commons Attribution License (http://creativecommons.org/licenses/by/2.0), which permits unrestricted use, distribution, and reproduction in any medium, provided the original work is properly cited.
$[5,18]$ and both genes harbour the majority of mutations also, but more infrequently, at codon 61 [21].

Colorectal cancer is the third most common cancer in the world with incidence rates varying up to 25 -fold between countries [22]; it has been postulated that approximately $80 \%$ of the observed differences in incidence rates between countries can be attributed to dietary factors [23]. Although analysis of dietary components has been performed in relation to incidence of this cancer in general, the exact relationship of dietary factors to specific gene mutations and signalling pathway $600[18,19]$ and $K$-ras at codons 12 and $13[20]$ and 
alterations remains to be fully elucidated. To date, analysis of dietary factors in relation to oncogenically activated ERK pathway members in colorectal cancer has only been performed in a limited number of studies and almost exclusively with regard to $K$-ras mutation. One study reported that low calcium intake and high monounsaturated fat intake were associated with $\mathrm{K}$-ras mutated colorectal tumours [24] but this was not confirmed subsequently [14]. Another report linked polyunsaturated fatty acid consumption to K-ras mutated colorectal tumours [25]. At present, very few data exist describing $B R A F$ mutations in relation to dietary factors, with only one study analysing folate, fibre and alcohol consumption and showing no association between $B R A F$ mutation and these dietary constituents [26].

The present study aimed to investigate the relationship between BRAF and K-ras mutations in 186 adenocarcinomas from the EPIC Norfolk cohort and clinicopathological features, lifestyle and dietary factors. This study is the most comprehensive to date examining dietary factors and $B R A F$ mutations in colorectal cancer. Dietary factors which have not been previously tested for association with $K$-ras mutations in colorectal cancer were also explored.

\section{Methods}

\section{Study population}

The EPIC Norfolk cohort included 25639 healthy men and women aged between 45 and 79 years residing in Norfolk, United Kingdom. Study participants were recruited between 1993 to 1997, from whom information on lifestyle and diet was collected prospectively and who were followed up for incident cancers and other health endpoints. Exact cohort details, blood DNA extraction methods and data collection methods are described in detail elsewhere [27-29]. Ethical approval was obtained from the Norwich Local Research Ethics Committee.

\section{Case ascertainment and tissue samples}

Incident cases of colorectal cancer (International Statistical Classification of Diseases and Related Health Problems (ICD) 9th revision, 153.0-153.9, 154.0, and 154.1) were ascertained by matching study participants to the East Anglian Cancer Registry and Information Centre (ECRiC) in conjunction with data from the United Kingdom Office for National Statistics. Cases of colorectal cancer which developed after the first year following recruitment were used for analysis. As of June 2004, 291 participants in the Norfolk cohort were reported as having been diagnosed with colorectal cancer. For individuals from whom archival tissue was available, formalin-fixed, paraffin-embedded (FFPE) tissue blocks and histopathological reports were obtained from the Norfolk and Norwich University
Hospital. Clinicopathological data describing tumour location, Dukes' stage and differentiation were obtained from pathology reports and the ECRiC. Available for this study were 186 adenocarcinoma and 16 adenoma samples from 189 individuals (adenocarcinoma and separate adenoma tissue was obtained from the same individual in 13 cases, adenoma tissue in isolation was resected from 3 individuals and adenocarcinoma tissue in isolation was resected from 173 individuals). The 16 adenomas were either tubular or tubulo-villous adenomas with low grade dysplasia, none displayed significant serrated architecture, and all adenomas were considered together as a single group of pre-malignant neoplasms.

\section{DNA extraction}

FFPE sample blocks were cut into $4 \mu \mathrm{m}$ sections. One section was stained with haematoxylin and eosin and was used for histological identification of adenoma, adenocarcinoma and normal cell types within the sample. This section was used as a template for isolation of the different cell types from a further five $4 \mu \mathrm{m}$ sections. Following histological examination, 186 adenocarcinomas and 16 adenomas were identified. Different tissue types were macrodissected and scraped into $240 \mu \mathrm{l}$ of Buffer PKD with $10 \mu \mathrm{l}$ of Proteinase K (both obtained from RNEasy FFPE kits, QIAGEN, Valencia, USA). Samples were agitated at $150 \mathrm{rpm}$ at $55.0^{\circ} \mathrm{C}$ for $4-6$ days. Tissue digestion was checked after 3 days and samples which still had visible amounts of tissue had a further $10 \mu$ l of Proteinase $\mathrm{K}$ added for the remainder of the incubation. Samples were then incubated at $80.0^{\circ} \mathrm{C}$ for 15 minutes in order to partially reverse formaldehyde modification of the nucleic acids and to denature any residual protein. DNA concentration was then checked using Nanodrop ND-1000 Spectrophotometer (Labtech International Ltd, Ringmer, UK).

\section{Mutation detection}

PCR amplification of the known mutation hotspots of $B R A F$ and $K$-ras was performed. BRAF exon 11 was amplified using primers 11F (5'-CCT GTA TCC CTC TCA GGC ATA AGG-3') and 11R (5'-GAA CAG TGA ATA TTT CCT TTG ATG-3'). BRAF exon 15 was amplified using primers $15 \mathrm{~F}$ (5'-CTT CAT AAT GCT TGC TCT GAT AGG-3') and 15R (5'-GCA TCT CAG GGC CAA AAA T-3'). PCR products were generated using $5 \mathrm{ng}-2 \mu \mathrm{g}$ of template DNA. KOD Hot Start DNA Polymerase kits (Novagen, Madison, USA) were used to make the following reaction mixture: $2.5 \mu \mathrm{l} \times 10 \mathrm{PCR}$ Buffer for KOD Hot Start DNA Polymerase, $1 \mu \mathrm{l}$ primers, forward and reverse $\left(10 \mu \mathrm{M}\right.$ each), $1 \mu \mathrm{l} \mathrm{MgSO}_{4}$ (25 mM), $2 \mu \mathrm{l}$ dNTPs ( $2 \mathrm{mM}$ each), $0.25 \mu \mathrm{l}$ KOD DNA Polymerase and made up to a total reaction volume of $25 \mu \mathrm{l}$ with water. The reactions involved a denaturation 
step at $94.0^{\circ} \mathrm{C}$ for 5 minutes followed by 45 cycles of $94.0^{\circ} \mathrm{C}$ for 15 seconds, 30 seconds at annealing temperatures of $58.1^{\circ} \mathrm{C}$ and $58.4^{\circ} \mathrm{C}$ for $B R A F$ exons 11 and 15 respectively and $72.0^{\circ} \mathrm{C}$ for 30 seconds. Final extension was $72^{\circ} \mathrm{C}$ for 5 minutes. To detect successful amplifications, $5 \mu \mathrm{l}$ of each reaction mixture was separated on a $3 \%$ agarose gel containing $1 \mu \mathrm{g} / \mathrm{ml}$ ethidium bromide, and visualised under UV light.

$K$-ras exon 1 was amplified using previously described primers [30]. K-ras exon 2 was amplified using primers 2F (5'-GCA CTG TAA TAA TCC AGA CTG TGT TTC-3') and 2R (5'-GAC AGC TTA TTA TAT TCA ATT TAA AC-3'). The PCR reaction mixture and reaction conditions were as described for $B R A F$ except that annealing temperatures of $60.0^{\circ} \mathrm{C}$ and $55.0^{\circ} \mathrm{C}$ were used for amplification of $K$-ras exons 1 and 2 respectively. For dideoxysequencing, the remaining PCR amplification product mixture $(20 \mu \mathrm{l})$, following visualisation on agarose gels, was purified using Multiscreen filter plates (Millipore, Billerica, USA) according to the manufacturer's instructions and subjected to direct sequencing by ABI3730xl Platform sequencer (Applied Biosystems, Warrington, UK). Forward and reverse strands were both sequenced. Every sample was PCR amplified and sequenced a minimum of twice on each strand.

$K$-ras exon 1 was also analysed at codons 12 and 13 with pyrosequencing using a previously described assay which has been shown to be of greater sensitivity than dideoxysequencing when detecting base changes at these positions [31]. Both methods were used to maximise the sensitivity of mutation detection at the highly mutated codons 12 and 13 in exon 1. Following PCR generation of an 82 bp amplicon (reaction mixture as described for $B R A F$, primers and primer annealing temperatures are described elsewhere [31]) reaction mixture was subjected directly to pyrosequencing. Pyrosequencing was performed on two independent PCR products at each of the bases analysed, such that 6 independent reactions were undertaken for each sample (twice at bases 1 and 2 of codon 12 and twice at base 2 of codon 13).

\section{Microsatellite stability status determination}

Determination of microsatellite stability status is described elsewhere (Gay L et al., submitted). In brief, six microsatellites were used for microsatellite stability status determination: BAT25, BAT26, BAT40, D2S123, D5S346 and D17S250. PCR primers for amplification of cancer DNA were labelled with 5'6-FAM and primers for amplification of corresponding non-cancerous DNA from the same individual (obtained from blood samples) were labelled with 5'HEX. PCR amplicons covering each marker were analysed for changes in size using an ABI3730xl Platform sequencer with a Genescan 500 ROX size standard (Applied Biosystems, Warrington,
UK), and ABI Peak Scanner software (version 1.0). If two or more of the six markers in cancer DNA demonstrated a deviation in size from the same markers analysed in corresponding non-cancerous DNA, the cancer sample was classified as showing microsatellite instability (MSI). If one or none of the markers demonstrated size deviation, the sample was classified as microsatellite stable (MSS).

\section{Lifestyle and other exposure assessment}

Height and weight information were obtained using a baseline health examination upon recruitment between 1993 and 1997 and body mass index (BMI) calculated. Health and lifestyle questionnaires administered at the same time recorded information pertaining to hormone replacement therapy (HRT), smoking habits including smoking status (current, former or never) and pack years of cigarette use (defined as 20 cigarettes a day for a year) and habitual physical activity, assessed using questions referring to present activity at the time of questionnaire administration. Those with low physical activity were defined as those with a sedentary job with no recreational activity, a sedentary job with less than 0.5 hours of recreational activity per day, or a standing job with no recreational activity. High physical activity included those with activity levels above these definitions. Details of the measurements and questionnaires used for attainment and assessment of these data are described elsewhere [28,32,33].

Dietary assessment was performed using seven day food diaries ( $7 \mathrm{dd}$ ) which were completed at recruitment. This method of dietary assessment has been previously validated and is described in detail elsewhere [27]. Diaries were completed at recruitment. Food descriptions and portion size estimates were converted into weights of foods and food group data derived. Intakes of meat, fish, fruit and vegetables were assessed as the weights of foods contributing to these food groups. Meat classifications included red, processed and white meats and white and fatty fish types. Red meat was defined as beef, lamb, mutton, pork, veal, rabbit and venison, including composite dishes and excluding offal. White meat was defined as chicken, turkey, duck, guinea fowl, goose, pheasant, grouse and other birds, and as all meat/joints simply cooked or in composite dishes. Processed meat was defined as meat that had undergone smoking, curing, salting or the addition of chemical preservatives. White fish was defined as fish where fat is concentrated in the liver rather than the flesh, such as cod, haddock etc. and fatty fish was defined as fish where fat is distributed throughout the flesh, such as herring and mackerel. Shellfish were not included in either fish category. Fruit consumption was defined as intake of fruits in all forms, including fruit included in composite 
dishes, but excluding fruit from juices, cereals and jams. Vegetable consumption was defined as intake of vegetables in all forms excluding potatoes, legumes, herbs, pickles and chutneys, and tomato sauces in canned products. Alcohol, fat, vitamin, calcium and macronutrient intakes were calculated using the Data into Nutrients for Epidemiological Research (DINER) program, which is described in detail elsewhere [34].

\section{Statistical analysis}

Analysis of lifestyle and patient characteristics was performed using chi-squared $\left(\chi^{2}\right)$ tests for categorical data and analysis of variance (ANOVA) tests for all continuous numerical data. For this analysis, all 186 adenocarcinomas were classified as BRAF or $K$-ras mutated or wildtype. For additional testing, K-ras mutated adenocarcinomas were classified by mutation type as either those cancers exhibiting $G$ to A transitions or cancers exhibiting any other mutation type. Clinicopathological cancer features were examined in relation to these mutation categories. Dukes' stage was classified as early Dukes' stage (A and B) and late Dukes' stage (C and D). Tumour location was classified as proximal colonic and distal colonic/rectal. Cancers of other origins (i.e. appendix or secondary metastases) were omitted from location testing. Differentiation was determined by a histopathologist and classified as moderately/well differentiated or poorly differentiated and microsatellite instability status as MSS or MSI. Lifestyle factors, including smoking status (current/former/never), physical activity (high/low), alcohol consumption (g/day, continuous), low-density (mmol/l, continuous) and high-density lipoprotein blood concentrations (mmol/l, continuous), triglyceride blood concentrations (mmol/l, continuous) and plasma vitamin C concentrations ( $\mu \mathrm{mol} / \mathrm{l}$, continuous) were also tested for association with the defined mutation categories. Continuous dietary variables were tested for association with mutation including meat, fruit and vegetable, fat, vitamin, and fibre and macronutrient, including calcium, variables, in their relevant unit of consumption. A probability value of less than or equal to 0.05 was considered to be statistically significant. No adjustment was made for multiple testing. All testing was performed using SPSS version 16.0 (SPSS Inc, Chicago, USA).

\section{Results \\ BRAF and K-ras mutation frequencies in colorectal adenocarcinomas and adenomas}

The type and distribution of the mutations observed in $B R A F$ and $K$-ras in colorectal neoplasms are described in Table 1 with examples in Figure 1. Of the 186 colorectal adenocarcinoma samples analysed, 29 (15.6\%) harboured a mutation in $B R A F$. All BRAF mutations were the V600E type due to $\mathrm{T}$ to A transversion in exon 15, although a previously reported synonymous SNP (rs56101602) was detected in one adenocarcinoma sample in exon 11 . None of the 16 adenomas analysed harboured BRAF mutations in either exon 11 or 15 .

Dideoxysequencing analysis of exons 1 and 2 of $K$-ras identified 30 mutations in the 16 adenoma and 186 adenocarcinoma samples. In addition to those mutations identified with dideoxysequencing, pyrosequencing of $K$-ras codons 12 and 13 demonstrated the presence a further 14 mutations in the colorectal tumour samples analysed, confirming the increased sensitivity of this method. In total, $K$-ras mutations in $41 / 186$ different adenocarcinomas (22.0\%) were identified. A previously unreported double mutation observed using dideoxysequencing, at codons 19 and 20 (Figure 1) was not in the region analysed with pyrosequencing. Only $1 / 30$ (3.3\%) mutations in codons 12 and 13 identified with dideoxysequencing was not identified with pyrosequencing when subsequently analysed. Thirty-three (78.6\%) of the base changes observed in $K$-ras in adenocarcinomas were in codon 12 . Seven $(16.7 \%)$ were in codon 13 . Two other base changes ( $4.8 \%$ of total) were observed in codons 19 and 20 of the same cancer.

Of the 16 colorectal adenomas analysed, 7 harboured non-wildtype $K$-ras DNA sequences. Six mutations were identified in exon 1 , one, at codon 89 , in exon 2 . The $C$ to A transversion at the second position of codon 89 produced a stop codon. The remaining 6 mutations in exon 1 were observed to be oncogenically activating base changes in codons 12 and 13. Known oncogenically activating mutations were therefore observed in $37.5 \%$ of the adenomas tested. Of the 7 adenoma samples which exhibited non-wildtype $K$-ras sequence, 2 adenomas were identified without accompanying adenocarcinoma. Of the 5 adenomas which were resected from individuals from whom independently presenting adenocarcinoma was also resected, two exhibited an identical mutation in both the adenoma and adenocarcinoma. Three exhibited mutations in the adenoma tissue alone with no evidence of a corresponding mutation in the accompanying adenocarcinoma samples.

Testing of the co-incidence of mutation in BRAF and $K$-ras demonstrated that the prevalence of mutation in these two genes were inversely associated $(\mathrm{p}=0.009$, $\left.\chi^{2}\right)$. Fifty-nine adenocarcinomas presented with either $B R A F$ or $K$-ras mutation, only one of which harboured both.

\section{Lifestyle and clinicopathological factors in relation to BRAF and K-ras mutations}

Analysis of the distribution of cancers with $B R A F$ or $K$-ras mutations according to clinicopathological and lifestyle variables is presented in Table 2. Proximal colonic location, poor differentiation and MSI were all 
Table 1 The type and distribution of mutations in BRAF and $K$-ras in the 186 adenocarcinoma and 16 adenoma tissues available from EPIC Norfolk

\begin{tabular}{|c|c|c|c|}
\hline & \multicolumn{3}{|c|}{$B R A F$ mutation } \\
\hline & Mutations in adenocarcinomas & Mutations in adenomas & Total \\
\hline \multicolumn{4}{|c|}{ Codon 600: wildtype GTG } \\
\hline GAG (Val to Glu) & 29 & 0 & 29 \\
\hline \multirow[t]{3}{*}{ Total } & 29 & 0 & 29 \\
\hline & \multicolumn{3}{|c|}{ K-ras mutation } \\
\hline & Mutations in adenocarcinomas & Mutations in adenoma & Total \\
\hline \multicolumn{4}{|c|}{ Codon 12: wildtype GGT } \\
\hline GCT (Gly to Ala) & 7 & 1 & 8 \\
\hline GTT (Gly to Val) & 6 & 1 & 7 \\
\hline GAT (Gly to Asp) & 14 & 2 & 16 \\
\hline TGT (Gly to Cys) & 4 & 1 & 5 \\
\hline AGT (Gly to Ser) & 1 & 0 & 1 \\
\hline Undetermined* & 1 & 0 & 1 \\
\hline \multicolumn{4}{|c|}{ Codon 13: wildtype GGC } \\
\hline GAC (Gly to Asp) & 6 & 1 & 7 \\
\hline TGC (Gly to Cys) & 1 & 0 & 1 \\
\hline \multicolumn{4}{|c|}{ Codon 19: wildtype TTG } \\
\hline GTT (Leu to Phe) $)^{* *}$ & 1 & 0 & 1 \\
\hline \multicolumn{4}{|c|}{ Codon 20: wildtype ACG } \\
\hline GCG $(\text { Thr to Ala })^{* *}$ & 1 & 0 & 1 \\
\hline \multicolumn{4}{|c|}{ Codon 89: wildtype TCA } \\
\hline TTA (Ser to Stop) & 0 & 1 & 1 \\
\hline Total & 42 & 7 & 49 \\
\hline
\end{tabular}

*: One adenocarcinoma sample was classified as mutated by both sequencing methods but the base change identified was not consistent. Dideoxysequencing identified the base change as $G$ to $A$, pyrosequencing as $G$ to $C$. Repeated sequencing using both methods did not resolve this and as such the base change was unclassified. **: The two mutations observed in codons 19 and 20 were in the same adenocarcinoma.

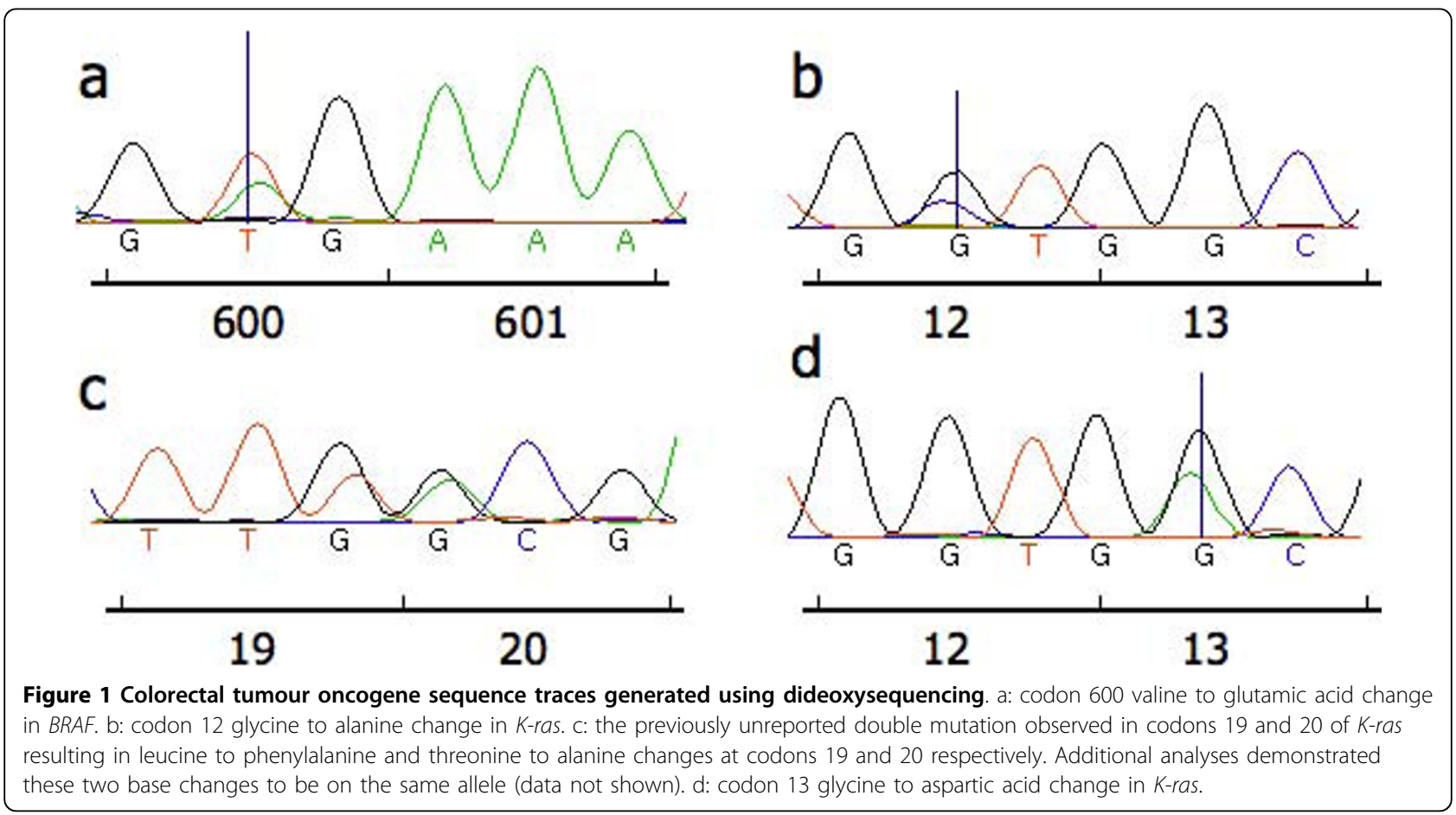


Table 2 Clinicopathological and lifestyle characteristics of colorectal cancer cases by BRAF or K-ras mutation status and $K$-ras mutated cancers by specific $K$-ras mutation types

\begin{tabular}{|c|c|c|c|c|c|c|c|c|c|}
\hline \multirow[b]{2}{*}{ Characteristic } & \multicolumn{3}{|c|}{$B R A F$ mutation } & \multicolumn{3}{|c|}{ K-ras mutation } & \multicolumn{3}{|c|}{ K-ras mutation type } \\
\hline & $\begin{array}{l}\text { Wildtype } \\
n=157^{\dagger}\end{array}$ & $\begin{array}{l}\text { Mutant } \\
n=29^{\dagger}\end{array}$ & $P^{\ddagger}$ & $\begin{array}{l}\text { Wildtype } \\
n=145^{\dagger}\end{array}$ & $\begin{array}{l}\text { Mutant } \\
n=41^{\dagger}\end{array}$ & $P^{\ddagger}$ & $\begin{array}{c}G \text { to } A \\
n=22^{+}\end{array}$ & $\begin{array}{c}\text { Other } \\
n=17^{\dagger}\end{array}$ & $P^{\neq}$ \\
\hline \multicolumn{10}{|l|}{ Sex } \\
\hline Male & $52.9(83)$ & $34.5(10)$ & & $46.9(68)$ & $61.0(25)$ & & $63.6(14)$ & $58.8(10)$ & \\
\hline Female & $47.1(74)$ & $65.5(19)$ & 0.07 & $53.1(77)$ & $39.0(16)$ & 0.11 & $36.4(8)$ & $41.2(7)$ & 0.76 \\
\hline Age at diagnosis (years) & $70.1(7.9)$ & $72.9(5.5)$ & $0.07^{*}$ & $71.1(7.1)$ & $68.5(8.9)$ & $0.06^{*}$ & $67.2(9.4)$ & $69.4(8.7)$ & $0.46^{*}$ \\
\hline \multicolumn{10}{|l|}{ Tumour location } \\
\hline Proximal colonic & $28.3(41)$ & $75.0(21)$ & & $33.1(44)$ & $45.0(18)$ & & $42.9(9)$ & $52.9(9)$ & \\
\hline Distal colonic/Rectal & $71.7(104)$ & $25.0(7)$ & $<0.001$ & $66.9(89)$ & $55.0(22)$ & 0.17 & $57.1(12)$ & $47.1(8)$ & 0.54 \\
\hline \multicolumn{10}{|l|}{ Differentiation } \\
\hline Well/Moderate & $90.6(125)$ & $59.3(16)$ & (FET) & $85.8(109)$ & $84.2(32)$ & & $80.0(16)$ & $87.5(14)$ & (FET) \\
\hline Poor & $9.4(13)$ & $40.7(11)$ & $<0.001$ & $14.2(18)$ & $15.8(6)$ & 0.80 & $20.0(4)$ & $12.5(2)$ & 0.67 \\
\hline \multicolumn{10}{|l|}{ Dukes' Stage } \\
\hline$A / B$ & $54.5(73)$ & $57.7(15)$ & & $61.9(78)$ & $29.4(10)$ & & $27.8(5)$ & $33.3(5)$ & (FET) \\
\hline$C / D$ & $45.5(61)$ & $42.3(11)$ & 0.76 & $38.1(48)$ & $70.6(24)$ & 0.001 & $72.2(13)$ & $66.7(101)$ & 1.00 \\
\hline \multicolumn{10}{|l|}{ MSI status } \\
\hline MSS & 90.8 (129) & $42.9(12)$ & (FET) & 78.4 (105) & $100.0(36)$ & & a & a & \\
\hline MSI & $9.2(13)$ & $57.1(16)$ & $<0.001$ & $21.6(29)$ & $0.0(0)$ & 0.002 & a & a & a \\
\hline BMI $\left(\mathrm{kg} / \mathrm{m}^{2}\right)$ & $27.3(4.3)$ & $26.6(4.3)$ & $0.41^{*}$ & $27.0(4.3)$ & $27.9(4.3)$ & $0.26^{*}$ & $28.1(4.3)$ & $27.7(4.7)$ & $0.74^{*}$ \\
\hline Alcohol intake $(\mathrm{g} / \mathrm{d})$ & $9.9(15.3)$ & $5.1(10.4)$ & $0.11^{*}$ & $8.6(14.1)$ & $11.1(16.6)$ & $0.36^{*}$ & $11.1(18.0)$ & $8.6(11.1)$ & $0.62^{*}$ \\
\hline \multicolumn{10}{|l|}{ Smoking status } \\
\hline Current & $9.9(15)$ & $13.8(4)$ & & $11.4(16)$ & $7.3(3)$ & & $13.6(3)$ & $0.0(0)$ & \\
\hline Former & $46.1(70)$ & $48.3(14)$ & & $45.7(64)$ & $48.8(20)$ & & $45.5(10)$ & $52.9(9)$ & \\
\hline Never & $44.1(67)$ & $37.9(11)$ & 0.74 & $42.9(60)$ & $43.9(18)$ & 0.75 & $40.9(9)$ & $47.1(8)$ & 0.29 \\
\hline \multicolumn{10}{|l|}{ Physical activity } \\
\hline Low & $66.7(104)$ & $69.0(20)$ & & $66.0(95)$ & 70.7 (29) & & $63.6(14)$ & $76.5(13)$ & \\
\hline High & $33.3(52)$ & $31.0(9)$ & 0.81 & $34.0(49)$ & $29.3(12)$ & 0.57 & $36.4(8)$ & $23.5(4)$ & 0.49 \\
\hline \multicolumn{10}{|l|}{ HRT satatus } \\
\hline Current & $9.6(7)$ & $5.3(1)$ & & $9.2(7)$ & $6.2(1)$ & & b & b & \\
\hline Former & $16.4(12)$ & $21.1(4)$ & & $17.1(13)$ & $18.8(3)$ & & b & $\mathrm{b}$ & \\
\hline Never & $74.0(54)$ & $73.7(14)$ & 0.78 & $73.7(56)$ & $75.0(12)$ & 0.93 & b & $\mathrm{b}$ & b \\
\hline LDL (mmol/l) & $4.14(1.1)$ & $4.06(1.1)$ & $0.75^{*}$ & $4.19(1.2)$ & $3.91(0.8)$ & $0.19^{*}$ & $3.85(0.7)$ & $3.93(1.0)$ & $0.79^{*}$ \\
\hline $\mathrm{HDL}(\mathrm{mmol} / \mathrm{l})$ & $1.30(0.4)$ & $1.33(0.3)$ & $0.63^{*}$ & $1.33(0.4)$ & $1.19(0.4)$ & $0.04^{*}$ & $1.16(0.4)$ & $1.16(0.4)$ & $0.96^{*}$ \\
\hline Triglyceride $(\mathrm{mmol} / \mathrm{l})$ & $2.11(1.2)$ & $1.94(1.1)$ & $0.48^{*}$ & $2.02(1.1)$ & $2.34(1.3)$ & $0.12^{*}$ & $2.23(1.2)$ & $2.59(1.5)$ & $0.43^{*}$ \\
\hline Plasma vitamin $C(\mu \mathrm{mol} / \mathrm{l})$ & $52.0(24.3)$ & $48.0(20.9)$ & $0.44^{*}$ & $52.5(24.8)$ & $47.5(20.0)$ & $0.28^{*}$ & $45.4(19.7)$ & $50.0(20.9)$ & $0.52^{*}$ \\
\hline
\end{tabular}

${ }^{\ddagger} \mathrm{P}$ values determined by $\chi^{2}$ test or Fisher's exact test when one or more expected values were less than 5 (denoted by FET). *: ANOVA tests used to calculate p-values. Results presented as [ $n(\%)]$ or [mean ( \pm SD)]. HRT: hormone replacement therapy. MSI: Microsatellite instability. MSS: Microsatellite stable. ${ }^{\dagger}$ Not all individuals had data for each variable, in these cases these individuals were omitted from the test. For HRT testing only females were analysed, for which 92 had data available. ${ }^{a}$ Microsatellite instability was not tested relative to different $K$-ras mutation types as none of the cancers harbouring $K$-ras mutation exhibited microsatellite instability. ${ }^{\mathrm{b}}$ HRT status was not tested relative to different $K$-ras mutation types due to the low numbers of cases available for testing.

associated with $B R A F$ mutation (all $\mathrm{p}<0.001$ ). The prevalence of cancers with $B R A F$ mutation was higher in females and in individuals with a later age at diagnosis, although these differences failed to reach statistical significance (both $\mathrm{p}=0.07$ ).

A higher proportion of cancers harbouring K-ras mutation was found to have later Dukes' stage ( $C$ or $D$ rather than $\mathrm{A}$ or $\mathrm{B})(\mathrm{p}=0.001)$ and to be microsatellite stable $(\mathrm{MSS})(\mathrm{p}=0.002)$. Of the 36 cancers with available microsatellite stability data and $K$-ras mutation, all were MSS. Cases of cancers harbouring mutated $\mathrm{K}$-ras also demonstrated earlier age at diagnosis, although this association failed to reach statistical significance $(p=0.06)$. Cases with $K$-ras mutation had significantly lower mean blood HDL cholesterol concentrations than those with wildtype $K$-ras $(1.19 \mathrm{mmol} / \mathrm{l}$ versus $1.33 \mathrm{mmol} / \mathrm{l}$; $\mathrm{p}=0.04)$.

\section{Dietary factors and BRAF and K-ras mutations}

None of the dietary factors tested displayed a statistically significant association with $B R A F$ mutations in colorectal cancers. Individuals harbouring $K$-ras mutated cancers 
had a statistically significantly increased mean white meat consumption: $29.5 \mathrm{~g} / \mathrm{d}$ versus $17.4 \mathrm{~g} / \mathrm{d}, \mathrm{p}<0.001$ (Table 3 ).

\section{Lifestyle, dietary and clinicopathological factors of colorectal cancers in relation to K-ras mutation type}

Of the $42 \mathrm{~K}$-ras mutations observed in colorectal cancers, 22 were $\mathrm{G}$ to A transitions. In order to assess the relevance of this observation, individuals with $K$-ras mutated cancers exhibiting this specific $G$ to A base change were compared with individuals harbouring $K$ ras mutated cancers with all other mutation types such that $K$-ras mutations were classified as ' $G$ to A' or 'other'. One sample, harbouring a double mutation at codons 19 and 20 was omitted from the testing due to the base changes being of both classifications. A second sample was classified as mutated by both dideoxysequencing and pyrosequencing methods. However, the two methods described a $G$ to $A$ and a $G$ to $C$ base change respectively, confirmed following repeated testing. This case was also omitted from this analysis. Analysis of the distribution of cancers with different $K$-ras mutation types according to clinicopathological and lifestyle variables is summarised in Table 2: none of the clinicopathological features or lifestyle exposures tested were associated with either classification of K-ras mutation.

All dietary variables were tested for association with either $K$-ras mutation classification. Cancers harbouring $\mathrm{G}$ to A transitions in $K$-ras were found in individuals with a significantly lower consumption of fruit compared with those individuals harbouring other $K$-ras mutation types $(\mathrm{p}=0.02): 155 \mathrm{~g} / \mathrm{d}$ versus $247 \mathrm{~g} / \mathrm{d}$. A reduced consumption of vegetables was also observed in those individuals with $K$-ras $\mathrm{G}$ to A base changes in their cancers, although this did not reach statistical significance $(p=0.07)$.

Table 3 Dietary intakes stratified by BRAF and $K$-ras mutation status

\begin{tabular}{|c|c|c|c|c|c|c|}
\hline \multirow[b]{2}{*}{ Dietary factor } & \multicolumn{3}{|c|}{ BRAF mutation } & \multicolumn{3}{|c|}{ K-ras mutation } \\
\hline & Wildtype $n=156$ & Mutant $n=29$ & $P^{\neq}$ & Wildtype $n=144$ & Mutant $n=41$ & $P^{\ddagger}$ \\
\hline \multicolumn{7}{|l|}{ Meat } \\
\hline Red Meat $(\mathrm{g} / \mathrm{d})$ & $37(28.9)$ & $40(24.5)$ & 0.60 & $38(28.4)$ & $33(27.2)$ & 0.31 \\
\hline Processed Meat (g/d) & $24(19.7)$ & $25(14.3)$ & 0.81 & $25(18.7)$ & $23(19.8)$ & 0.62 \\
\hline Red + Processed Meat (g/d) & $61(37.1)$ & $65(28.5)$ & 0.59 & $63(35.9)$ & $56(35.4)$ & 0.29 \\
\hline White Meat $(\mathrm{g} / \mathrm{d})$ & $21(20.2)$ & $17(15.5)$ & 0.29 & $17(18.0)$ & $30(22.1)$ & $<0.001$ \\
\hline White Fish (g/d) & $17(15.7)$ & $17(26.5)$ & 0.98 & $18(19.3)$ & $14(10.7)$ & 0.28 \\
\hline Fatty Fish (g/d) & $12(20.0)$ & $10(12.1)$ & 0.64 & $11(17.5)$ & $14(23.4)$ & 0.33 \\
\hline \multicolumn{7}{|l|}{ Fruit and vegetables } \\
\hline Fruit $(\mathrm{g} / \mathrm{d})$ & $170(133.1)$ & $193(170.9)$ & 0.42 & $168(143.0)$ & $191(125.8)$ & 0.36 \\
\hline Vegetables (g/d) & $136(68.3)$ & $150(70.9)$ & 0.29 & $136(66.6)$ & $145(76.1)$ & 0.43 \\
\hline \multicolumn{7}{|l|}{ Fat } \\
\hline Total Fat (g/d) & $71(22.9)$ & $71(23.7)$ & 1.00 & $71(22.4)$ & $75(25.0)$ & 0.32 \\
\hline PUFA (g/d) & $13(5.3)$ & $13(5.7)$ & 0.96 & $13(5.1)$ & $14(6.2)$ & 0.20 \\
\hline MUFA (g/d) & $25(8.1)$ & $24(7.5)$ & 0.77 & $24(7.9)$ & $26(8.5)$ & 0.29 \\
\hline SFA $(g / d)$ & $27(10.2)$ & $28(11.7)$ & 0.84 & $27(10.3)$ & $28(10.7)$ & 0.59 \\
\hline \multicolumn{7}{|l|}{ Vitamins } \\
\hline B2[riboflavin] (mg/d) & $2(0.6)$ & $2(0.6)$ & 0.95 & $2(0.6)$ & $2(0.6)$ & 0.67 \\
\hline B3[niacin] (mg/d) & $18(5.5)$ & $18(6.7)$ & 0.69 & $18(5.9)$ & $19(4.7)$ & 0.40 \\
\hline B6[pyroxidine] ( $\mu \mathrm{g} / \mathrm{d})$ & $2(0.6)$ & $2(0.6)$ & 0.96 & $2(0.6)$ & $2(0.6)$ & 0.35 \\
\hline B9[folate] $(\mu \mathrm{g} / \mathrm{d})$ & $259(71.9)$ & $257(73.8)$ & 0.89 & $258(73.4)$ & $260(67.7)$ & 0.89 \\
\hline $\mathrm{B} 12(\mu \mathrm{g} / \mathrm{d})$ & $6(5.5)$ & $5(4.0)$ & 0.40 & $6(5.2)$ & $6(5.4)$ & 0.96 \\
\hline$C(\mathrm{mg} / \mathrm{d})$ & $85(48.7)$ & $87(38.8)$ & 0.82 & $85(45.5)$ & $87(53.4)$ & 0.78 \\
\hline$D(\mu \mathrm{g} / \mathrm{d})$ & $3(2.2)$ & $4(2.3)$ & 0.69 & $3(2.1)$ & $4(2.6)$ & 0.53 \\
\hline \multicolumn{7}{|l|}{ Fibre and Macronutrients } \\
\hline Total Energy (MJ/d) & $8(2.1)$ & $8(1.8)$ & 0.85 & $8(2.1)$ & $8(2.0)$ & 0.51 \\
\hline Carbohydrate (g/d) & $235(68.2)$ & $250(58.5)$ & 0.25 & $238(68.6)$ & $236(60.9)$ & 0.87 \\
\hline Protein $(\mathrm{g} / \mathrm{d})$ & $70(15.1)$ & $68(14.8)$ & 0.48 & $70(15.4)$ & $72(13.6)$ & 0.29 \\
\hline $\operatorname{NSP}(g / d)$ & $14(5.0)$ & $16(7.4)$ & 0.15 & $14(5.8)$ & $15(4.1)$ & 0.53 \\
\hline Calcium (mg/d) & 779 (235.9) & $821(220.5)$ & 0.37 & 787 (239.8) & $783(212.7)$ & 0.92 \\
\hline
\end{tabular}

${ }^{\ddagger} \mathrm{P}$ values determined by ANOVA. Results presented as [mean ( \pm SD)]. PUFA: polyunsaturated fatty acid. MUFA: monounsaturated fatty acid. SFA: saturated fatty acid. NSP: non-starch polysaccharide. For one case for which mutational status had been determined no dietary data was available. Therefore, for all testing with dietary factors the number of combined cases in the wildtype and mutated groups available for analysis was 185. 


\section{Discussion}

The data presented herein suggest that $B R A F$ and $K$-ras mutations arise in an almost mutually exclusive manner in distinct subsets of colorectal cancer, that differ in terms of clinicopathological features, dietary factors and lifestyle exposures. BRAF mutation in colorectal cancers was observed at a frequency of $15.6 \%$ and $K$-ras mutation at $22.0 \%$. These frequencies are at the high and low ends of the ranges previously reported for mutations in these genes in colorectal cancer: 4-13\% for BRAF [2-9] and $20-50 \%$ for $K$-ras $[10,12-17,35]$. The mutually exclusive nature of these two mutation types, as shown in this and other studies $[3,5,7,18,36]$ may explain this: increased prevalence of $B R A F$ mutation in this sample set may be consistent with a reduction in $\mathrm{K}$-ras mutation frequency.

$B R A F$ mutation was strongly associated with cancer of proximal colonic location, poor differentiation and microsatellite instability (all $\mathrm{p}<0.001$ ). BRAF mutation and proximal colonic location have been linked in previous reports [5]. Microsatellite instability has been linked to proximal location [37] and has been consistently linked to $B R A F$ mutation in colorectal cancer [3,4,6]: one review described $B R A F$ mutation as a hallmark' of MSI tumours [38]. Poor differentiation has also been linked to BRAF mutation in previous studies $[39,40]$ as well as microsatellite instability [41]. Taken together, these data confirm that the clinicopathological signature of $B R A F$ mutated colorectal cancer includes proximal location, microsatellite instability and poor differentiation. This is consistent with this distinct subset of tumours arising by a mechanism of microsatellite instability, which is strongly associated with $B R A F$ mutation. In contrast to this, analysis of $K$-ras mutations demonstrated an association with microsatellite stability $(\mathrm{p}=0.002)$; an observation reported previously $[4,6,42]$. In this report $K$-ras mutation was more prevalent in cancers of later Dukes' stage (C and D). This observation has been made in some previous reports $[13,15]$ but not in others $[2,11,12,17,20,35,43]$. Additionally, the largest study to date on $\mathrm{K}$-ras mutations in colorectal cancer, analysing 4268 cases, reported an association between $K$-ras mutation in colorectal cancer and poor prognosis [44], suggesting an association between $K$-ras mutation and more advanced colorectal cancer. The testing presented herein demonstrates the independent clinicopathological nature of colorectal cancers with either BRAF or $K$-ras mutations.

Analysis of dietary factors stratified by colorectal cancer gene mutation type showed that none of the dietary factors tested were positively or negatively associated with $B R A F$ mutation. This study is the first to undertake a comprehensive analysis of $B R A F$ mutations in colorectal cancer and their relationship to dietary factors. One previous report analysed folate, alcohol and fibre consumption and found no association with $B R A F$ mutation [26], observations which were confirmed in this study. The detailed analysis presented here has demonstrated further the independence of $B R A F$ mutation relative to dietary intakes using a comprehensive analysis of twenty four individual dietary constituents.

Analysis of $K$-ras mutations in colorectal cancers in relation to dietary factors demonstrated that mutation in $K$-ras was associated with increased white meat consumption ( $\mathrm{p}<0.001)$. Furthermore, analysis of $K$-ras mutation type identified those individuals harbouring $K$ ras mutated cancers with $\mathrm{G}$ to $\mathrm{A}$ transitions as consuming less fruit $(\mathrm{p}=0.02)$ and vegetables, although the reduction in vegetable consumption was of marginal statistical significance $(\mathrm{p}=0.07)$. Individuals harbouring $K$ ras mutated cancers also had lower blood HDL cholesterol concentrations than those harbouring cancers with wildtype $K$-ras genes $(\mathrm{p}=0.04)$, an association requiring validation in future studies. The association between increased white meat consumption and $K$-ras mutations in colorectal cancer requires confirmation in larger studies and in vitro mechanistic investigations. However, plausible mechanisms have been postulated which may explain reduced fruit and vegetable consumption and increased prevalence of $\mathrm{G}$ to $\mathrm{A}$ transitions. Fruits and vegetables contain bioactive compounds, such as flavanols, capable of inhibiting nitroso compound formation [45]. Nitroso compounds are capable of inducing guanine base alkylation which, if not repaired, can lead to $\mathrm{G}$ to A base transitions [46]. Therefore, low fruit and vegetable consumption is consistent with $G$ to $A$ transitions in tumours, as demonstrated in this study. This study did not confirm observations made in a previous study of $K$-ras mutated colorectal tumours being associated with low calcium and high monounsaturated fat intake [24]. These observations were also tested in another large population based study, which also failed to detect this association [14]. Another finding linking polyunsaturated fatty acid types to $K$-ras mutated tumours [25] was also not confirmed in the data presented here.

In addition to the 186 cancer samples analysed, 16 unselected adenomas were also tested for mutation in $B R A F$ and $K$-ras. No BRAF mutations were observed in any of the adenomas. A previous analysis of 113 unselected sporadic colorectal adenomas detected $B R A F$ mutations at a frequency of only $2.8 \%$ [8]. However, in serrated adenomas mutation frequencies for $B R A F$ of 30 to $50 \%$ of cases have been described [36,47]. Because of the low number of adenomas available for analysis and the lack serrated adenomas in this sample set (none 
were included), the observation that none of the 16 adenomas tested harboured $B R A F$ mutation was expected.

In contrast to $B R A F, 6(37.5 \%)$ adenomas harboured oncogenically activating mutations in $K$-ras, a prevalence consistent with previous reports $[8,48]$. In addition to this, a novel K-ras mutation was observed in a single adenoma. This mutation was not observed in the corresponding cancer tissue. This point mutation in codon 89 produced a stop codon towards the end of exon 2 . This mutation is uncharacteristic of proto-oncogene transformation in that it would not lead to increased ERK signalling. However, the tumour suppressor function of wildtype KRAS protein has been previously described [49] and as such a putative cancer promoting effect of such a truncating mutation in K-ras cannot be discounted.

Although the number of adenomas tested was too low to elucidate meaningful relationships between clinicopathological features, lifestyle exposures and dietary intakes, it is interesting to note the lack of $B R A F$ mutations observed compared to the relatively high prevalence of oncogenically activating mutations observed in K-ras $(37.5 \%)$. These observations are consistent with the later timing of $B R A F$ mutation in colorectal cancer development, which has been postulated previously [50], and is consistent with distinct subsets of colorectal tumours with $B R A F$ and $K$-ras mutations.

A strength of the current study is the use of prospective dietary and lifestyle data collected before the onset of disease as well as the use of $7 \mathrm{dd}$ records for dietary assessment, a method that has been shown to estimate diet more accurately than food frequency questionnaires when validated with urinary biomarkers [51]. Furthermore, such detailed dietary analysis regarding so many variables has not been previously attempted in relation to mutation of these genes, and as such this report contributes new information to the current knowledge of mutations in BRAF and $K$-ras in colorectal cancer and dietary intakes. The limitations inherent in our study of multiple statistical testing mean that the significant associations observed in this study would benefit from further validation. Adjustment for confounding variables in the statistical testing was not performed in this study. It has previously been described how logistic regression analyses performed on low sample sets leads to systematic bias (i.e. away from null), and overestimation of odds ratios [52]. Consequently, in order to prevent overestimation of dietary risk factors, this testing was not performed on the small sample sizes available. Further validation of the exploratory associations presented in this report would benefit from testing in studies with larger sample sets upon which confounding factors could be extensively explored.

\section{Conclusions}

$B R A F$ mutations are found in cancers with a clinicopathological signature of proximal colonic location, poor differentiation and microsatellite instability. Furthermore, the presence of $B R A F$ mutations in colorectal cancer is not associated with any of the dietary factors tested. Conversely, K-ras mutations are not characteristic of colorectal cancers with these clinicopathological features and are found in microsatellite stable colorectal cancers and are associated with a more advanced Dukes' stage. Unlike BRAF mutations, K-ras mutations, in general and specific types, appear to be associated with specific dietary factors. These data demonstrate the independent distribution of $B R A F$ and $K$-ras mutations in different subsets of colorectal cancer.

\section{Acknowledgements}

Thanks to Dr Jenny Keen for help with DNA extraction and Dr Catherine Wilson for her advice regarding K-ras mutations. Our thanks go to Professor Kay-Tee Khaw who helped coordinate the project. EPIC Norfolk is funded by Cancer Research UK and Medical Research Council.

\section{Author details}

${ }^{1}$ Medical Research Council Dunn Human Nutrition Unit, Wellcome Trust/MRC Building, Cambridge, CB2 OXY, UK. ${ }^{2}$ Medical Research Council Centre for Nutritional Epidemiology in Cancer Prevention and Survival, Department of Public Health and Primary Care, University of Cambridge, Cambridge CB1 8RN, UK. ${ }^{3}$ Norfolk and Waveney Cellular Pathology Network, Norfolk and Norwich University Hospital NHS Foundation Trust, Colney Lane, Norwich, NR4 7UY, UK. ${ }^{4}$ Department of Pathology, University of Cambridge,

Addenbrooke's Hospital, Cambridge CB2 2QQ, UK.

\section{Authors' contributions}

AN performed the sequencing analyses, statistical testing and composed the manuscript. PNM contributed to manuscript preparation and directed the display of statistical data. LJG performed the MSI analyses. RYB obtained access to and distributed the human tissue samples. RNL and AM compiled and provided the dietary data. MJA contributed to study design, histopathological analysis of the samples, manuscript preparation and supervision of the project. JCC and SAR contributed to study design and coordination. All authors read and approved the manuscript, except SAR. Sheila Rodwell's initial contributions were of great help and guidance during the concept and initiation stages of this study. With great regret, Sheila's untimely passing in June 2009 meant that she was unable to witness the outcome of the research described here.

\section{Competing interests}

The authors declare that they have no competing interests.

Received: 9 October 2009 Accepted: 16 March 2010

Published: 16 March 2010

\section{References}

1. Marshall CJ: Small GTPases and cell cycle regulation. Biochem Soc Trans 1999, 27(4):363-370.

2. Calistri D, Rengucci C, Seymour I, Lattuneddu A, Polifemo AM, Monti F, Saragoni L, Amadori D: Mutation analysis of p53, K-ras, and BRAF genes in colorectal cancer progression. J Cell Physiol 2005, 204(2):484-488.

3. Fransen $K$, Klintenas M, Osterstrom A, Dimberg J, Monstein HJ, Soderkvist P: Mutation analysis of the BRAF, ARAF and RAF- 1 genes in human colorectal adenocarcinomas. Carcinogenesis 2004, 25(4):527-533.

4. Lee S, Cho NY, Choi M, Yoo EJ, Kim JH, Kang GH: Clinicopathological features of CpG island methylator phenotype-positive colorectal cancer and its adverse prognosis in relation to KRAS/BRAF mutation. Pathol Int 2008, 58(2):104-113. 
5. Li WQ, Kawakami K, Ruszkiewicz A, Bennett G, Moore J, lacopetta B: BRAF mutations are associated with distinctive clinical, pathological and molecular features of colorectal cancer independently of microsatellite instability status. Mol Cancer 2006, 5:2.

6. Nagasaka T, Koi M, Kloor M, Gebert J, Vilkin A, Nishida N, Shin SK, Sasamoto H, Tanaka N, Matsubara N, et al: Mutations in both KRAS and BRAF may contribute to the methylator phenotype in colon cancer. Gastroenterology 2008, 134(7):1950-1960, 1960 e1951.

7. Samowitz WS, Albertsen H, Herrick J, Levin TR, Sweeney C, Murtaugh MA, Wolff RK, Slattery ML: Evaluation of a large, population-based sample supports a $\mathrm{CpG}$ island methylator phenotype in colon cancer. Gastroenterology 2005, 129(3):837-845.

8. Yuen ST, Davies H, Chan TL, Ho JW, Bignell GR, Cox C, Stephens P, Edkins S, Tsui WW, Chan AS, et al: Similarity of the phenotypic patterns associated with BRAF and KRAS mutations in colorectal neoplasia. Cancer Res 2002, 62(22):6451-6455.

9. Ogino S, Kawasaki T, Kirkner GJ, Kraft P, Loda M, Fuchs CS: Evaluation of markers for CpG island methylator phenotype (CIMP) in colorectal cancer by a large population-based sample. J Mol Diagn 2007, 9(3):305-314.

10. Breivik J, Lothe RA, Meling Gl, Rognum TO, Borresen-Dale AL, Gaudernack G: Different genetic pathways to proximal and distal colorectal cancer influenced by sex-related factors. Int J Cancer 1997, 74(6):664-669.

11. Brink M, de Goeij AF, Weijenberg MP, Roemen GM, Lentjes MH, Pachen MM, Smits KM, de Bruine AP, Goldbohm RA, Brandt van den PA: Kras oncogene mutations in sporadic colorectal cancer in The Netherlands Cohort Study. Carcinogenesis 2003, 24(4):703-710.

12. Poehlmann A, Kuester D, Meyer F, Lippert H, Roessner A, Schneider-Stock R: K-ras mutation detection in colorectal cancer using the Pyrosequencing technique. Pathol Res Pract 2007, 203(7):489-497.

13. Samowitz WS, Curtin K, Schaffer D, Robertson M, Leppert M, Slattery ML: Relationship of Ki-ras mutations in colon cancers to tumor location, stage, and survival: a population-based study. Cancer Epidemiol Biomarkers Prev 2000, 9(11):1193-1197.

14. Slattery ML, Curtin K, Anderson K, Ma KN, Edwards S, Leppert M, Potter J, Schaffer D, Samowitz WS: Associations between dietary intake and Ki-ras mutations in colon tumors: a population-based study. Cancer Res 2000, 60(24):6935-6941.

15. Smith G, Carey FA, Beattie J, Wilkie MJ, Lightfoot TJ, Coxhead J, Garner RC, Steele RJ, Wolf CR: Mutations in APC, Kirsten-ras, and p53-alternative genetic pathways to colorectal cancer. Proc Natl Acad Sci USA 2002, 99(14):9433-9438.

16. Suchy B, Zietz C, Rabes HM: K-ras point mutations in human colorectal carcinomas: relation to aneuploidy and metastasis. Int J Cancer 1992, 52(1):30-33

17. Zhang $H$, Nordenskjold $B$, Dufmats $M$, Soderkvist $P$, Sun XF: K-ras mutations in colorectal adenocarcinomas and neighbouring transitional mucosa. Eur J Cancer 1998, 34(13):2053-2057.

18. Rajagopalan H, Bardelli A, Lengauer C, Kinzler KW, Vogelstein B, Velculescu VE: Tumorigenesis: RAF/RAS oncogenes and mismatch-repair status. Nature 2002, 418(6901):934

19. Davies H, Bignell GR, Cox C, Stephens P, Edkins S, Clegg S, Teague J, Woffendin H, Garnett MJ, Bottomley W, et al: Mutations of the BRAF gene in human cancer. Nature 2002, 417(6892):949-954.

20. Vogelstein B, Fearon ER, Hamilton SR, Kern SE, Preisinger AC, Leppert M, Nakamura Y, White R, Smits AM, Bos JL: Genetic alterations during colorectal-tumor development. N Engl J Med 1988, 319(9):525-532.

21. Bos JL: ras oncogenes in human cancer: a review. Cancer Res 1989, 49(17):4682-4689.

22. Parkin DM, Bray F, Ferlay J, Pisani P: Global cancer statistics, 2002. CA Cancer J Clin 2005, 55(2):74-108.

23. Cummings $\mathrm{JH}$, Bingham SA: Diet and the prevention of cancer. BMJ 1998, 317(7173):1636-1640.

24. Bautista D, Obrador A, Moreno V, Cabeza E, Canet R, Benito E, Bosch X Costa J: Ki-ras mutation modifies the protective effect of dietary monounsaturated fat and calcium on sporadic colorectal cancer. Cancer Epidemiol Biomarkers Prev 1997, 6(1):57-61.

25. Weijenberg MP, Luchtenborg M, de Goeij AF, Brink M, van Muijen GN, de Bruine AP, Goldbohm RA, Brandt van den PA: Dietary fat and risk of colon and rectal cancer with aberrant MLH1 expression, APC or KRAS genes. Cancer Causes Control 2007, 18(8):865-879.

26. Slattery ML, Curtin K, Sweeney C, Levin TR, Potter J, Wolff RK, Albertsen H, Samowitz WS: Diet and lifestyle factor associations with CpG island methylator phenotype and BRAF mutations in colon cancer. Int J Cancer 2007, 120(3):656-663

27. Bingham SA, Welch AA, McTaggart A, Mulligan AA, Runswick SA, Luben R, Oakes S, Khaw KT, Wareham N, Day NE: Nutritional methods in the European Prospective Investigation of Cancer in Norfolk. Public Health Nutr 2001, 4(3):847-858.

28. Day N, Oakes S, Luben R, Khaw KT, Bingham S, Welch A, Wareham N: EPICNorfolk: study design and characteristics of the cohort. European Prospective Investigation of Cancer. Br J Cancer 1999, 80(Suppl 1):95-103.

29. Riboli E, Kaaks R: The EPIC Project: rationale and study design. European Prospective Investigation into Cancer and Nutrition. Int J Epidemiol 1997, 26(Suppl 1):S6-14.

30. Wei S, Liang Z, Gao J, Wu S, Zhu H, Liu H, Liu T: Patterns of K-ras codon 12 and 13 mutations found in pancreatic adenocarcinoma of 30 Chinese patients by microdissection, PCR and direct sequencing. J Gastroenterol Hepatol 2005, 20(1):67-72.

31. Ogino S, Kawasaki T, Brahmandam M, Yan L, Cantor M, Namgyal C, MinoKenudson M, Lauwers GY, Loda M, Fuchs CS: Sensitive sequencing method for KRAS mutation detection by Pyrosequencing. J Mol Diagn 2005, 7(3):413-421.

32. Sargeant LA, Khaw KT, Bingham S, Day NE, Luben RN, Oakes S, Welch A, Wareham NJ: Cigarette smoking and glycaemia: the EPIC-Norfolk Study. European Prospective Investigation into Cancer. Int J Epidemiol 2001, 30(3):547-554.

33. Wareham NJ, Jakes RW, Rennie KL, Schuit J, Mitchell J, Hennings S, Day NE: Validity and repeatability of a simple index derived from the short physical activity questionnaire used in the European Prospective Investigation into Cancer and Nutrition (EPIC) study. Public Health Nutr 2003, 6(4):407-413.

34. Welch AA, McTaggart A, Mulligan AA, Luben R, Walker N, Khaw KT, Day NE, Bingham SA: DINER (Data Into Nutrients for Epidemiological Research) a new data-entry program for nutritional analysis in the EPIC-Norfolk cohort and the 7-day diary method. Public Health Nutr 2001, 4(6):1253-1265.

35. Boughdady IS, Kinsella AR, Haboubi NY, Schofield PF: K-ras gene mutations in adenomas and carcinomas of the colon. Surg Oncol 1992, 1(4):275-282.

36. Velho S, Moutinho C, Cirnes L, Albuquerque C, Hamelin R, Schmitt F, Carneiro F, Oliveira C, Seruca R: BRAF, KRAS and PIK3 CA mutations in colorectal serrated polyps and cancer: primary or secondary genetic events in colorectal carcinogenesis? BMC Cancer 2008, 8:255.

37. Loh K, Chia JA, Greco S, Cozzi SJ, Buttenshaw RL, Bond CE, Simms LA, Pike T, Young JP, Jass JR, et al: Bone morphogenic protein 3 inactivation is an early and frequent event in colorectal cancer development. Genes Chromosomes Cancer 2008, 47(6):449-460.

38. Jass JR: Colorectal cancer: a multipathway disease. Crit Rev Oncog 2006, 12(3-4):273-287

39. Ang PW, Li WQ, Soong R, lacopetta B: BRAF mutation is associated with the CpG island methylator phenotype in colorectal cancer from young patients. Cancer Lett 2009, 273(2):221-224.

40. Kambara T, Simms LA, Whitehall VL, Spring KJ, Wynter CV, Walsh MD, Barker MA, Arnold S, McGivern A, Matsubara N, et al: BRAF mutation is associated with DNA methylation in serrated polyps and cancers of the colorectum. Gut 2004, 53(8):1137-1144.

41. Soreide K, Slewa A, Stokkeland PJ, van Diermen B, Janssen EA, Soreide JA, Baak JP, Korner H: Microsatellite instability and DNA ploidy in colorectal cancer: potential implications for patients undergoing systematic surveillance after resection. Cancer 2009, 115(2):271-282.

42. Deng G, Kakar S, Tanaka H, Matsuzaki K, Miura S, Sleisenger MH, Kim YS: Proximal and distal colorectal cancers show distinct gene-specific methylation profiles and clinical and molecular characteristics. Eur $J$ Cancer 2008, 44(9):1290-1301.

43. Forrester K, Almoguera C, Han K, Grizzle WE, Perucho M: Detection of high incidence of K-ras oncogenes during human colon tumorigenesis. Nature 1987, 327(6120):298-303.

44. Andreyev HJ, Norman AR, Cunningham D, Oates J, Dix BR, lacopetta BJ, Young J, Walsh T, Ward R, Hawkins N, et al: Kirsten ras mutations in 
patients with colorectal cancer: the 'RASCAL II' study. Br J Cancer 2001, 85(5):692-696.

45. Lee SY, Munerol B, Pollard S, Youdim KA, Pannala AS, Kuhnle GG, Debnam ES, Rice-Evans C, Spencer JP: The reaction of flavanols with nitrous acid protects against $\mathrm{N}$-nitrosamine formation and leads to the formation of nitroso derivatives which inhibit cancer cell growth. Free Radic Biol Med 2006, 40(2):323-334.

46. Saffhill R, Margison GP, O'Connor PJ: Mechanisms of carcinogenesis induced by alkylating agents. Biochim Biophys Acta 1985, 823(2):111-145.

47. Chan TL, Zhao W, Leung SY, Yuen ST: BRAF and KRAS mutations in colorectal hyperplastic polyps and serrated adenomas. Cancer Res 2003, 63(16):4878-4881.

48. Rashid A, Zahurak M, Goodman SN, Hamilton SR: Genetic epidemiology of mutated K-ras proto-oncogene, altered suppressor genes, and microsatellite instability in colorectal adenomas. Gut 1999, 44(6):826-833.

49. James RM, Arends MJ, Plowman SJ, Brooks DG, Miles CG, West JD, Patek CE: K-ras proto-oncogene exhibits tumor suppressor activity as its absence promotes tumorigenesis in murine teratomas. Mol Cancer Res 2003, 1(11):820-825.

50. Sweeney C, Boucher KM, Samowitz WS, Wolff RK, Albertsen H, Curtin K, Caan BJ, Slattery ML: Oncogenetic tree model of somatic mutations and DNA methylation in colon tumors. Genes Chromosomes Cancer 2009, 48(1):1-9.

51. Day N, McKeown N, Wong M, Welch A, Bingham S: Epidemiological assessment of diet: a comparison of a 7-day diary with a food frequency questionnaire using urinary markers of nitrogen, potassium and sodium. Int J Epidemiol 2001, 30(2):309-317.

52. Nemes $\mathrm{S}$, Jonasson JM, Genell A, Steineck G: Bias in odds ratios by logistic regression modelling and sample size. BMC Med Res Methodol 2009, 9:56.

\section{Pre-publication history}

The pre-publication history for this paper can be accessed here: http://www. biomedcentral.com/1471-2407/10/99/prepub

doi:10.1186/1471-2407-10-99

Cite this article as: Naguib et al: Dietary, lifestyle and

clinicopathological factors associated with BRAF and K-ras mutations arising in distinct subsets of colorectal cancers in the EPIC Norfolk study. BMC Cancer 2010 10:99.

\section{Submit your next manuscript to BioMed Central and take full advantage of:}

- Convenient online submission

- Thorough peer review

- No space constraints or color figure charges

- Immediate publication on acceptance

- Inclusion in PubMed, CAS, Scopus and Google Scholar

- Research which is freely available for redistribution 